\title{
Pós-graduação em resíduos sólidos no Brasil: Estudo quantitativo e espacialização da produção de teses e dissertações em Programas de Excelência \\ Postgraduate in solid waste in Brazil: quantitative study and spacialization of excellence programs' theses and dissertations

\author{
Data de entrada: \\ $13 / 06 / 2018$ \\ 20/06/2018
} \\ Data de aprovação:
}

Túlio Queijo de Lima ${ }^{1 *} \mid$ Cristine Diniz Santiago² ${ }^{2}$ Érica Pugliesi ${ }^{2}$ | Flávio Roberto Araújo De Franceschi'

ORCID ID

Lima T. Q (D) https://orcid.org/0000-0003-1336-3698

Santiago C.D (D) https://orcid.org/0000-0003-0928-118X
DOI: https://doi.org/10.36659/dae.2020.009

Pugliesi E (D) https://orcid.org/0000-0003-4688-1387 De Franceschi, F.R.A (D) https://0000-0003-3493-0372

\section{Resumo}

No mundo contemporâneo, a gestão de resíduos sólidos (RS) constitui temática relevante para a sustentabilidade, sendo uma questão interdisciplinar que permeia as ciências ambientais, as engenharias e a saúde pública, entre outras. Assim, este artigo buscou analisar a ocorrência de teses e dissertações na temática de RS em Programas de Excelência de Pós-Graduação no Brasil, de acordo com a especificidade de áreas de avaliação. A metodologia baseou-se na revisão bibliográfica sistemática, sendo definidos termos de busca para pesquisa nos bancos de dados dos programas de pré-definidos. Os resultados evidenciam que, no escopo proposto, as áreas de engenharia sanitária e civil respondem pela maioria das publicações, geograficamente concentradas na região Sudeste, caracterizando uma assimetria regional. Portanto, nos programas de excelência, evidenciase a necessidade de pluralizar abordagens, garantindo a interdisciplinaridade que a área demanda. Destaca-se também a necessidade de articulação dos programas existentes, de forma a garantir a abordagem proposta.

Palavras-chave: Resíduos Sólidos. Pós-Graduação. Base de Dados. Espacialização de Informações. Acervo Digital.

\section{Abstract}

Waste management is a relevant issue for sustainability in the contemporary world. It consists of an interdisciplinary matter, permeating areas such as environmental sciences, engineering, public health, among others. Thus, this article analyses the occurrence of thesis and dissertations in the area of solid waste produced in Brazilian Post-Graduate Excellence Programs, according to specific evaluation areas. The method consisted of a Systematic bibliographic review, being defined research terms to look into pre-determined Post-Graduate Excellence Programs data basis. Results show that sanitation and civil engineering are to be accounted for the major part of publications, geographically concentrated in the Southeast, marking a regional asymmetry. Therefore, the waste area is mostly studied by engineering areas, revealing the need for an approach pluralization, in order to guarantee the required interdisciplinary approach. Articulation is also a necessity, as an attempt to guarantee the referred approach.

Keywords: Waste. Postgraduate studies. Database. Information spacialization. Digital Collection.

\footnotetext{
${ }^{1}$ Programa de Pós-Graduação em Engenharia Hidráulica e Saneamento. Escola de Engenharia de São Carlos. Universidade de São Paulo. São Paulo (SP), Brasil.

${ }_{2}^{2}$ Programa de Pós-Graduação em Ciências Ambientais. Centro de Ciências Biológicas e da Saúde. Universidade Federal de São Carlos. São Carlos (SP), Brasil.

*Autor correspondente: tulioqueijoagmail.com.
} 


\section{INTRODUÇãO}

\subsection{A questão dos resíduos sólidos}

O ser humano lida com os resíduos que gera desde que abandonou as atividades nômades e fixou-se no território. No decorrer das civilizações, criou-se uma associação histórica dos resíduos com a ideia de enfermidade e contaminação, uma vez que no passado as populações viviam sem mínimas medidas de limpeza ou saneamento ambiental (ACCURIO et al., 1998; FERREIRA e ANJOS, 2001). Como agravante, as epidemias contribuíram para a formação da representação social dos resíduos como aquilo que é necessário levar para longe e livrar-se, sendo que até a década de 1950 a temática esteve associada essencialmente à área da saúde pública (VELLOSO, 2008).

$\mathrm{Na}$ atualidade, a gestão de resíduos sólidos é destacada como uma das temáticas socioambientais relevantes para a sustentabilidade no meio urbano, junto a temas como o consumismo, consumo de energia, degradação de recursos naturais, desigualdades sociais, deficiências no saneamento básico (DODMAN, MCGRANAHAN e DALAL-CLAYTON, 2013). Tal destaque vai ao encontro da inserção dessa temática em diversos capítulos da Agenda 21 estabelecida na Conferência das Nações Unidas sobre Meio Ambiente e Desenvolvimento, em 1992 (CNUMAD, 1992; ZVEIBIL, 2002).

Em parte, o destaque para os resíduos sólidos deve-se ao aumento vertiginoso de sua geração desde a Revolução Industrial e à intensificação da urbanização, bem como à diversificação da composição dos produtos descartados. Isso porque o modo de produção contemporâneo busca desvalorizar aquilo que não é mais produto ou mercadoria (BUSS, 2002; SENG et al., 2010; MESJASZ-LECH, 2014; SILVA et al., 2014; MAVROPOULOS, TSAKONA e ANTHOULI, 2015; MARQUES, 2015).
A necessidade de uma abordagem integrada congregando diferentes visões para o enfrentamento de tais temáticas socioambientais, assim como outras temáticas das ciências ambientais, é premente (FONSECA, 2000; DODMAN, MCGRANAHAN e DALAL-CLAYTON, 2013). Essa necessidade surge em um contexto de uma crise de civilização na qual o raciocínio humano contemporâneo busca fracionar o conhecimento para aprofundar-se em questões individuais, num processo de especialização (LEFF, 2000).

No entanto, o meio ambiente e os processos que nele ocorrem são interdisciplinares, não se restringindo a uma única ciência ou a uma abordagem segmentada ou simplista, pois permeiam o campo de conhecimento de duas ou mais disciplinas. Nessa perspectiva, a evolução da vida humana e as consequentes pressões sobre o meio ambiente levam a problemáticas que necessitam de soluções interdisciplinares (LEFF, 2000; PHILIPPI JR., 2000).

A temática dos resíduos sólidos, em particular, tem como característica intrínseca a interdisciplinaridade, uma vez que congrega elementos sociais, econômicos, políticos, ambientais e de saúde (TCHOBANOGLOUS, THEISEN e VIGIL, 1993; SISINNO e OLIVEIRA, 2000). Zveibil (2002) considera que a partir da década de 1990 surgem novas abordagens e conceitos para a compreensão da complexidade e o enfrentamento dessa temática. 0 autor ainda destaca que esses tratamentos diversificados foram absorvidos por diferentes setores da sociedade.

A complexidade gerada pela pluralidade da temática de resíduos sólidos se contrapõe à urgência de soluções nacionais e internacionais adequadas (CORNIERI e FRACALANZA, 2010; SANTOS e GONÇALVES-DIAS, 2012; JACOBI, 2012; MARSHALL e FARAHBAKSH, 2013). Esse cenário destaca a importante e necessária continuidade da contribuição da pesquisa científica 
sobre resíduos sólidos, que apresenta grande diversidade de abordagens possíveis.

A conformação da pesquisa científica dá-se nas universidades em atividades que envolvem graduação e pós-graduação, estando também relacionada com o ensino. A presença da pesquisa na universidade e sua interação com o ensino têm acompanhado a trajetória da universidade brasileira desde a sua criação, na década de 1920.

\subsection{0 enquadramento da Pós-Graduação em Resíduos Sólidos no Brasil}

As primeiras atividades de pós-graduação no Brasil ocorreram no início da década de 1930, na proposta do Estatuto das Universidades Brasileiras - decreto $\mathrm{n}^{\circ}$ 19.851, de 11 de abril de 1931 -, na qual Francisco Campos propôs a implantação de um sistema de pós-graduação nos moldes europeus (SANTOS, 2003; VELLOSO, 2014; CACETE, 2014). Esse modelo foi implementado tanto no curso de Direito da Universidade do Rio de Janeiro como na Faculdade Nacional de Filosofia e na Universidade de São Paulo (SANTOS, 2003). Em 1946, com a publicação do decreto $n^{\circ} 21.321$, o termo pós-graduação foi introduzido oficialmente no país, e os cursos assim designados possuíam "por fim especial a formação sistemática de especialização profissional” (BRASIL, 1946). $\mathrm{Na}$ década de 1950 passaram a ser firmados acordos entre Estados Unidos e Brasil implicando em convênios entre escolas e universidades norteamericanas e brasileiras por meio do intercâmbio de estudantes, pesquisadores e professores (SANTOS, 2003).

Porém o grande impulso para o estabelecimento e a dispersão dos cursos de pós-graduação do Brasil ocorreu na década de 1960. No início da década houve uma iniciativa importante na Universidade do Brasil na área de Ciências Físicas e Biológicas seguindo o modelo das graduate schools, resultado de um convênio com a Fun- dação Ford, e outra na mesma universidade, na área de Engenharia, com a criação da Comissão Coordenadora dos Programas de Pós-Graduação em Engenharia - COPPE (SANTOS, 2003). Nesse período deu-se também a implantação de cursos de mestrado e doutorado em áreas específicas na Universidade de Brasília, na Escola Superior de Agricultura de Viçosa, na Universidade Federal Rural do Rio de Janeiro, e os cursos de pósgraduação no ITA (SANTOS, 2003).

A implantação formal dos cursos de pós-graduação no Brasil ocorreu, definitivamente, em 1965, a partir do Parecer no 977/65 de 3 de dezembro de 1965 do Conselho Federal de Educação (CFE), emitido por Newton Lins Buarque Sucupira (SANTOS, 2003; VELLOSO, 2014), segundo o qual o modelo de pós-graduação a ser implantado era adequado à nova concepção de universidade, oriundo dos "países mais desenvolvidos". 0 Parecer 977 fazia a distinção entre cursos latu sensu e strictu sensu e estabelecia a pós-graduação conforme o modelo norte-americano (SANTOS, 2003), partindo da consideração de que os cursos de mestrado e doutorado constituem um lugar privilegiado de produção do conhecimento, dada a centralidade que a pesquisa científica deve neles assumir (SANTOS e AZEVEDO, 2009).

A Reforma Universitária de 1968 foi base para o estabelecimento da moderna pós-graduação (VELLOSO, 2014) ao serem criadas condições propícias para que as instituições de ensino superior passassem a articular - para a formação de recursos humanos de alto nível de qualificação - as atividades de ensino e de pesquisa, que até então - salvo raras exceções - estavam relativamente desconectadas (MARTINS, 2009). A política de implantação desse projeto buscou satisfazer dois quesitos fundamentais de atuação: a necessidade futura de mão de obra especializada para preencher novos empregos a partir do desenvolvimento econômico previsto e a necessidade de estimular a formação de cientistas, 
pesquisadores e técnicos que fossem aptos a gerar novos conhecimentos (VELLOSO, 2014).

A avaliação dos programas de pós-graduação foi definida pela Coordenação de Aperfeiçoamento de Pessoal de Nível Superior (CAPES) em 1998, sendo considerada atividade essencial para assegurar e manter a qualidade da Pós-Graduação no país (CAPES, 2016a). A Portaria nº 1.418/1998 do Ministério da Educação regulamenta a classificação dos cursos de pós-graduação de acordo com um padrão de qualidade pré-definido, em uma escala crescente de 1 a 7 (BRASIL, 1998). De acordo com o Plano Nacional da Pós-Graduação 2011-2020, a CAPES considera os programas classificados com as notas 5, 6 e 7 como programas de excelência, sendo a nota 5 conferida aos programas de excelência nacional e as notas 6 e 7 de excelência internacional (CAPES, 2013).

Essa classificação expressa que tais programas possuem produção científica consolidada e divulgação em periódicos internacionais de excelência, bem como prêmios, intercâmbio de pesquisadores com instituições de ponta, internacionalização dos projetos de pesquisa, infraestrutura de qualidade e alta inserção social. Dentre os 3.678 programas de pós-graduação ativos no país, 416 são considerados de excelência (CAPES, 2016a).

Os programas de pós-graduação são classificados em 48 áreas de avaliação, definidas a partir de três colégios - Ciências da Vida; Ciências Exatas, Tecnológicas e Interdisciplinar; e Humanidades - e nove grandes áreas (CAPES, 2016b). Dentre as grandes áreas de avaliação, a ocorrência da temática de resíduos sólidos está presente explicitamente na área de avaliação 'Engenharias I - Engenharia Sanitária' sob o título "RESÍDUOS SÓLIDOS, DOMÉSTICOS E INDUSTRIAIS”, conforme a tabela de áreas do conhecimento da CAPES (CAPES, 2016b).
No entanto, a temática "Resíduos Sólidos" é complexa e passível de diversas abordagens, deixando de estar restrita apenas à área de avaliação 'Engenharias l', e sua ocorrência ser identificada em pesquisas de diversas áreas de avaliação.

A partir dessa premissa, este artigo justifica-se ao considerar a importância da temática de resíduos sólidos dentre as áreas constituintes do saneamento básico. Além disso, a Política Nacional de Resíduos Sólidos - Lei 12.305/2010 - regulamentada pelo decreto 7.404/2010, define em seu art. $8^{\circ}$ inciso VII, a pesquisa científica e tecnológica como instrumento da política pública.

Nesse sentido, o presente artigo tem por objetivo analisar a ocorrência da pesquisa científica sintetizada em teses e dissertações na temática de resíduos sólidos em Programas de Excelência de Pós-Graduação no Brasil de acordo com a especificidade de áreas de avaliação.

\section{METODOLOGIA}

A definição da metodologia a ser adotada para o levantamento pretendido baseou-se no método da Revisão Bibliográfica Sistemática (RBS). Trata-se de uma metodologia que busca avançar a revisão bibliográfica convencional a partir de três etapas elementares: planejamento de pesquisa, execução e análise dos resultados. Assim, a RBS é aplicável a uma pesquisa estruturada, na qual o processo de levantamento dos dados deve seguir uma sequência definida (BIOLCHINI et al., 2007). A seguir é apresentada a sequência metodológica do artigo.

Partiu-se do recorte por área de avaliação de acordo com a classificação da CAPES. A definição das áreas de avaliação baseou-se na definição de gestão de resíduos sólidos de Tchobanoglous, Theisen e Vigil (1993). Os autores destacam a interdisciplinaridade da área, que deve estar em consonância com premissas das 
áreas de saúde pública, engenharia, economia, preservação ambiental e ciências sociais. Ademais, os autores ainda destacam a interface da área com funções administrativas, financeiras, legais e de planejamento.

Nessa perspectiva, é a busca de soluções para a gestão de resíduos sólidos que propicia tal interdisciplinaridade, sendo os principais campos de conhecimento envolvidos: as ciências econômicas, saúde pública, engenharia, geografia, planejamento local e regional, comunicação, ciência dos materiais, ciências políticas e ciências ambientais (TCHOBANOGLOUS, THEISEN e VIGIL, 1993).

A busca realizada no banco de dados da CAPES resultou em um universo de 32 programas de pós-graduação de excelência internacional, com avaliações seis e sete. Na Tabela 1 são apresentadas as áreas de avaliação e respectivas áreas básicas definidas como filtros para a referida pesquisa dos programas no banco de dados da CAPES.

Tabela 1 - Áreas de Avaliação e Áreas Básicas da CAPES selecionadas para a pesquisa.

\begin{tabular}{|c|c|}
\hline Área de Avaliação & Área Básica \\
\hline Ciências Ambientais & Ciências Ambientais \\
\hline Administração, Ciências Contábeis e Turismo & Administração \\
\hline Interdisciplinar & Sociais e Humanidades \\
\hline Planejamento Urbano e Regional / Demografia & Demografia \\
\hline Engenharias I & Engenharia Civil \\
\hline Engenharias I & Engenharia Sanitária \\
\hline Planejamento Urbano e Regional / Demografia & Planejamento Urbano e Regional \\
\hline Saúde Coletiva & Saúde Coletiva \\
\hline Saúde Pública & Saúde Coletiva \\
\hline Engenharias III & Engenharia de Produção \\
\hline
\end{tabular}

Fonte: Elaborada pelos autores.

Posteriormente foram definidos seis termos de busca para pesquisa junto aos bancos de dissertações e teses dos 32 programas de excelência identificados. As palavras definidas buscaram abranger diversas abordagens possíveis na área dos resíduos sólidos. Sendo assim, os termos de busca escolhidos foram: aterro; catador (es); ciclo de vida; coleta seletiva; compostagem; resíduo (s); e resíduos sólidos. No caso de palavras de possível ocorrência no singular e plural, as buscas foram realizadas em duplicata.
A partir da busca no banco de teses e dissertações de cada programa ${ }^{1}$ foi possível realizar o levantamento da produção de teses e dissertações na área, sendo essa a base de análise dos resultados. Concomitantemente, foi possível a identificação de elementos sobre os bancos de dados de teses e dissertações, que contribuíram para a discussão acerca da disponibilização do conhecimento científico na área. A Fig. 1 apresenta um fluxograma da metodologia adotada no artigo.

\footnotetext{
${ }^{1} \mathrm{O}$ banco de dados do Programa de Pós-Graduação em Engenharia Civil da COPPE/UFRJ não possui opção de busca por título ou palavra-chave, de forma que a busca neste caso foi realizada individualmente nas 1.744 dissertações e 703 teses disponíveis até setembro de 2016.
} 


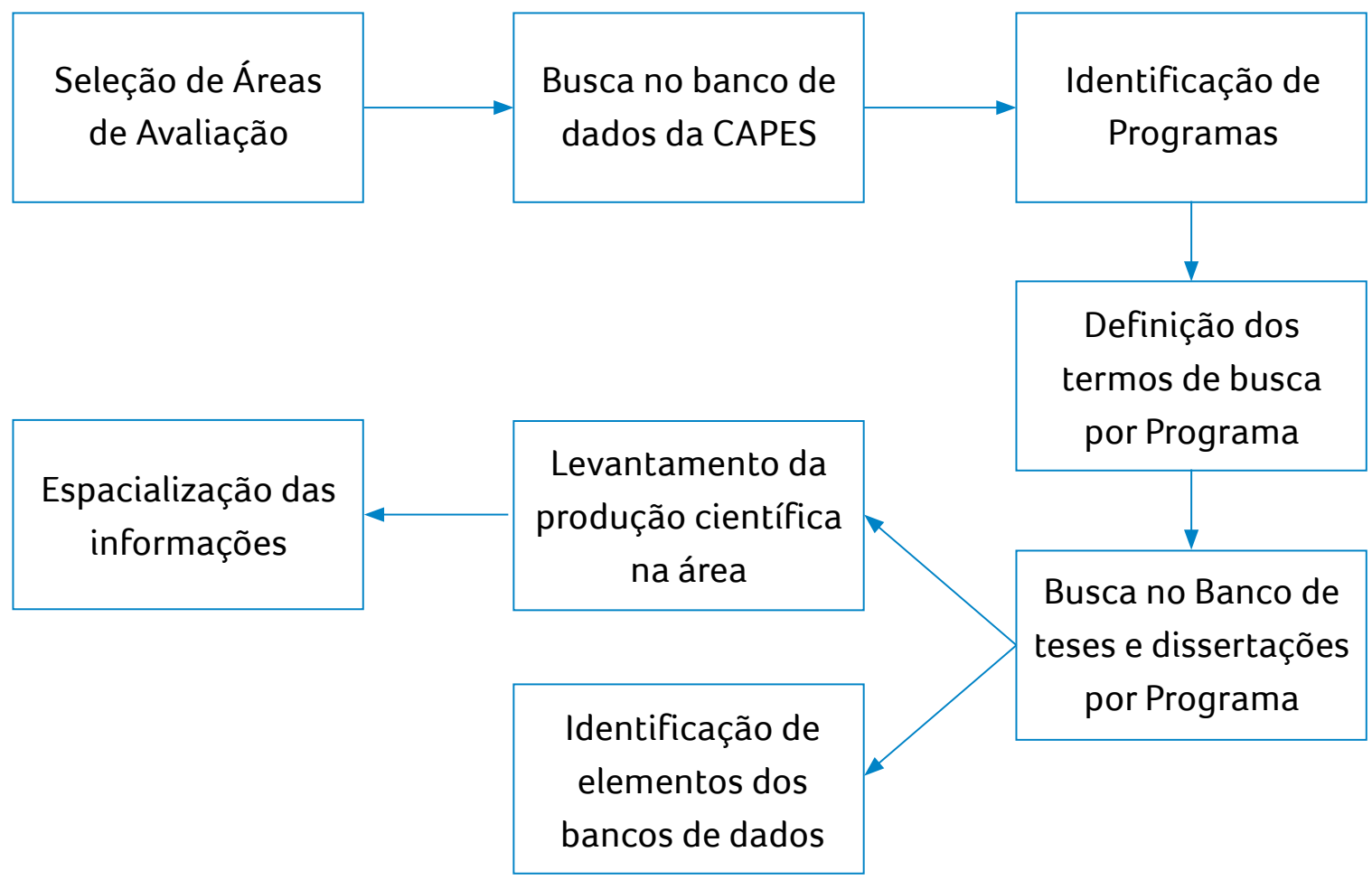

Figura 1 - Fluxograma das etapas metodológicas.

Fonte: Elaborada pelos autores.

\section{RESULTADOS E DISCUSSÃO}

A primeira busca realizada utilizando os termos de busca pré-definidos foi realizada no banco de teses e dissertações da CAPES, apresentando um total de 41.105 resultados, detalhados para cada palavra-chave na Tabela 2. Na Fig. 2, observa-se o percentual de respostas obtidas para cada termo de busca.
Tabela 2 - Resultados da busca inicial no banco de teses e dissertações da CAPES.

\begin{tabular}{|c|c|}
\hline Termos de busca & Resultados \\
\hline Aterro & 1.678 \\
\hline Catador (es) & 997 \\
\hline Ciclo de Vida & 4.147 \\
\hline Coleta Seletiva & 658 \\
\hline Compostagem & 715 \\
\hline Resíduo (s) & 28.150 \\
\hline Resíduos Sólidos & 4.760 \\
\hline TOTAL & $\mathbf{4 1 . 1 0 5}$ \\
\hline
\end{tabular}




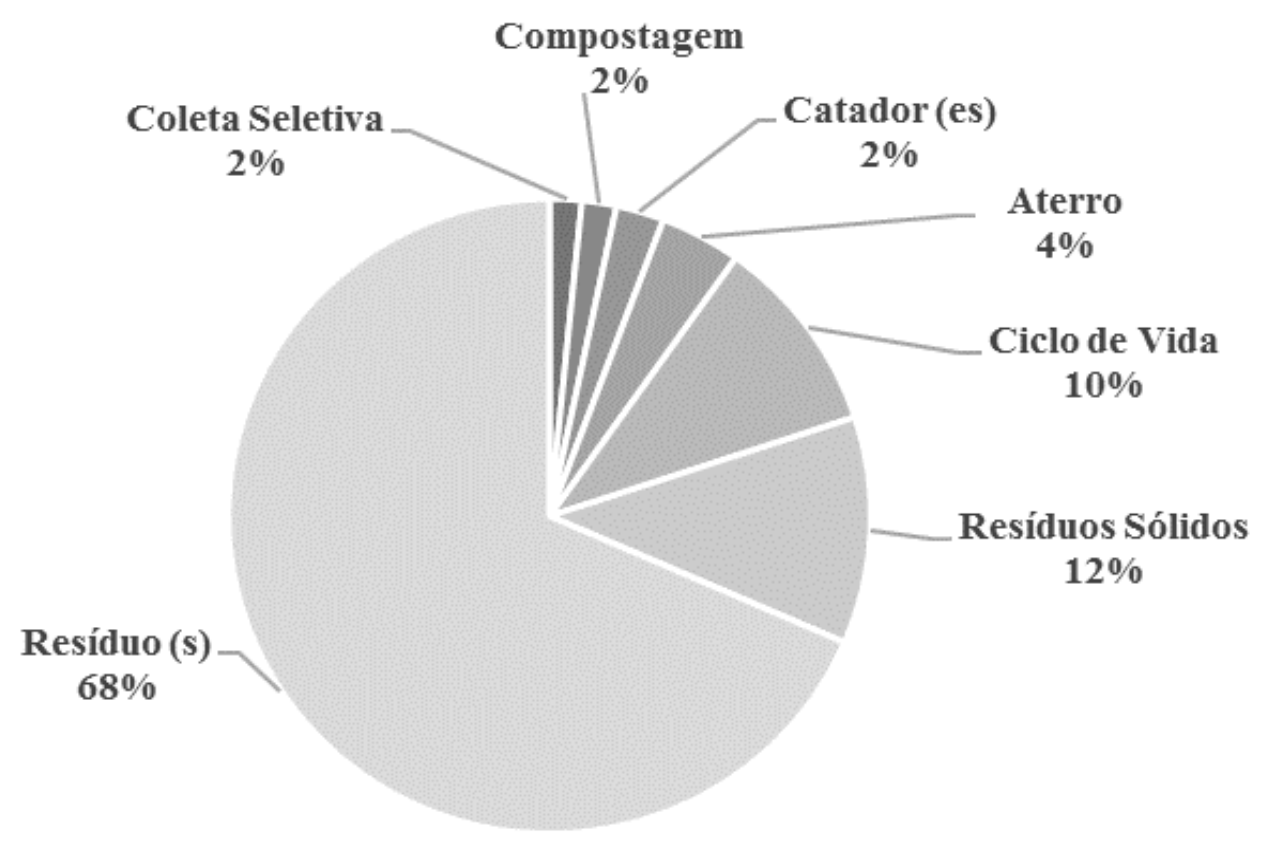

Figura 2 - Resultados dos termos de busca para o banco de teses e dissertações da CAPES.

Fonte: Elaborada pelos autores.

A Tabela 2 e a Fig. 2 apresentam um panorama geral da temática resíduos sólidos a partir dos termos de busca utilizados nesta pesquisa. Ressalta-se o resultado mais expressivo para o termo de busca "resíduo(s)", considerando-se que esse termo é utilizado em outros contextos e áreas do conhecimento, para expressar outros conceitos.

Posteriormente, selecionadas as áreas descritas na Tabela 1 foram identificados um total de 660 programas de pós-graduação ativos no país. A partir da identificação dos programas de pós-graduação de excelência internacional, que possuem notas seis e sete na última avaliação da CAPES, observa-se um total de 32 programas universo amostral desta pesquisa.

A Tabela 3 apresenta os 32 programas identificados, a instituição correspondente, a área básica e área de avaliação, e a respectiva nota da avaliação CAPES de cada programa. 
Tabela 3 - Identificação dos programas de Pós-Graduação de excelência internacional.

\begin{tabular}{|c|c|c|c|c|}
\hline $\begin{array}{l}\text { NOME DO PROGRAMA EM } \\
\text { FUNCIONAMENTO }\end{array}$ & INSTITUIÇÃO & ÁREA BÁSICA & ÁREA DE AVALIAÇÃO & $\begin{array}{l}\text { NOTA } \\
\text { CAPES }\end{array}$ \\
\hline CIÊNCIA AMBIENTAL & UNIVERSIDADE DE SÃO PAULO & \multirow{3}{*}{ CIÊNCIAS AMBIENTAIS } & \multirow{3}{*}{ CIÊNCIAS AMBIENTAIS (I) } & 6 \\
\hline $\begin{array}{l}\text { DESENVOLVIMENTO } \\
\text { SUSTENTÁVEL }\end{array}$ & UNIVERSIDADE DE BRASÍLIA & & & 6 \\
\hline ECOLOGIA APLICADA & $\begin{array}{l}\text { UNIVERSIDADE.DE SÃO PAULO/ } \\
\text { ESALQ }\end{array}$ & & & 7 \\
\hline ADMINISTRAÇÃO & FUNDAÇÃO GETÚLIO VARGAS/RJ & \multirow{3}{*}{ ADMINISTRAÇÃO } & \multirow{3}{*}{$\begin{array}{l}\text { ADMINISTRAÇÃO, CIÊNCIAS } \\
\text { CONTÁBEISE TURISMO (II) }\end{array}$} & 6 \\
\hline ADMINISTRAÇÃO & $\begin{array}{l}\text { UNIVERSIDADE FEDERAL DE } \\
\text { MINAS GERAIS }\end{array}$ & & & 6 \\
\hline ADMINISTRAÇÃO DE EMPRESAS & FUNDAÇÃO GETÚLIO VARGAS/SP & & & 7 \\
\hline $\begin{array}{l}\text { POLITICA CIENTÍFICA E } \\
\text { TECNOLÓGICA }\end{array}$ & $\begin{array}{l}\text { UNIVERSIDADE ESTADUAL DE } \\
\text { CAMPINAS }\end{array}$ & \multirow{3}{*}{ SOCIAIS E HUMANIDADES } & \multirow{3}{*}{ INTERDISCIPLINAR (III) } & 6 \\
\hline $\begin{array}{l}\text { POLÍTICAS PÚBLICASE } \\
\text { FORMAÇÃO HUMANA }\end{array}$ & $\begin{array}{l}\text { UNIVERSIDADE DO ESTADO DO } \\
\text { RIO DE JANEIRO }\end{array}$ & & & 6 \\
\hline $\begin{array}{c}\text { INTERDISCIPLINAREM CIÊNCIAS } \\
\text { HUMANAS }\end{array}$ & $\begin{array}{l}\text { UNIVERSIDADE FEDERAL DE } \\
\text { SANTA CATARINA }\end{array}$ & & & 6 \\
\hline DEMOGRAFIA & $\begin{array}{l}\text { UNIVERSIDADE ESTADUAL DE } \\
\text { CAMPINAS }\end{array}$ & \multirow{2}{*}{ DEMOGRAFIA } & \multirow{2}{*}{$\begin{array}{l}\text { PLANEJAMENTO URBANO E } \\
\text { REGIONAL / DEMOGRAFIA (IV) }\end{array}$} & 6 \\
\hline DEMOGRAFIA & $\begin{array}{l}\text { UNIVERSIDADE FEDERAL DE } \\
\text { MINAS GERAIS }\end{array}$ & & & 7 \\
\hline $\begin{array}{l}\text { RECURSOS HÍDRICOSE } \\
\text { SANEAMENTO AMBIENTAL }\end{array}$ & $\begin{array}{l}\text { UNIVERSIDADE FEDERAL DO RIO } \\
\text { GRANDE DO SUL }\end{array}$ & \multirow{6}{*}{ ENGENHARIA CIVIL } & \multirow{8}{*}{ ENGENHARIASI (V) } & 6 \\
\hline $\begin{array}{c}\text { ENGENHARIA CIVIL (RECURSOS } \\
\text { HÍDRICOS) }\end{array}$ & $\begin{array}{l}\text { UNIVERSIDADE FEDERAL DO } \\
\text { CEARÁ }\end{array}$ & & & 6 \\
\hline ENGENHARIA CIVIL & $\begin{array}{c}\text { UNIVERSIDADE FEDERAL DO RIO } \\
\text { DE JANEIRO }\end{array}$ & & & 7 \\
\hline ENGENHARIA CIVIL & $\begin{array}{l}\text { UNIVERSIDADE FEDERAL DE } \\
\text { SANTA CATARINA }\end{array}$ & & & 6 \\
\hline ENGENHARIA CIVIL & $\begin{array}{l}\text { PONTIFÍCIA UNIVERSIDADE } \\
\text { CATÓLICA DO RIO DE JANEIRO }\end{array}$ & & & 6 \\
\hline ENGENHARIA CIVIL & $\begin{array}{c}\text { UNIVERSIDADE FEDERAL DO RIO } \\
\text { GRANDE DO SUL }\end{array}$ & & & 7 \\
\hline $\begin{array}{l}\text { ENGENHARIA HIDRÁULICAE } \\
\text { SANEAMENTO }\end{array}$ & $\begin{array}{l}\text { UNIVERSIDADE DE SÃO PAULO/ } \\
\text { SÃO CARLOS }\end{array}$ & \multirow{2}{*}{ ENGENHARIA SANITÁRIA } & & 7 \\
\hline $\begin{array}{l}\text { SANEAMENTO, MEIO AMBIENTEE } \\
\text { RECURSOS HÍDRICOS }\end{array}$ & $\begin{array}{l}\text { UNIVERSIDADE FEDERAL DE } \\
\text { MINAS GERAIS }\end{array}$ & & & 7 \\
\hline ENGENHARIA DE PRODUÇÃO & $\begin{array}{l}\text { UNIVERSIDADE FEDERAL DE } \\
\text { PERNAMBUCO }\end{array}$ & \multirow{3}{*}{ ENGENHARIA DE PRODUÇÃO } & \multirow{3}{*}{ ENGENHARIAS III (VI) } & 6 \\
\hline ENGENHARIA DE PRODUÇÃO & $\begin{array}{l}\text { UNIVERSIDADE FEDERAL DO RIO } \\
\text { GRANDE DO SUL }\end{array}$ & & & 6 \\
\hline PLANEJAMENTO ENERGÉTICO & $\begin{array}{c}\text { UNIVERSIDADE FEDERAL DO RIO } \\
\text { DE JANEIRO }\end{array}$ & & & 6 \\
\hline $\begin{array}{l}\text { PLANEJAMENTO URBANOE } \\
\text { REGIONAL }\end{array}$ & $\begin{array}{c}\text { UNIVERSIDADE FEDERAL DO RIO } \\
\text { DE JANEIRO }\end{array}$ & \multirow{2}{*}{$\begin{array}{l}\text { PLANEJAMENTO URBANOE } \\
\text { REGIONAL }\end{array}$} & \multirow{2}{*}{$\begin{array}{l}\text { PLANEJAMENTO URBANO E } \\
\text { REGIONAL / DEMOGRAFIA (VII) }\end{array}$} & 6 \\
\hline $\begin{array}{l}\text { PLANEJAMENTO URBANO E } \\
\text { REGIONAL }\end{array}$ & $\begin{array}{l}\text { UNIVERSIDADE FEDERAL DO RIO } \\
\text { GRANDE DO SUL }\end{array}$ & & & 6 \\
\hline $\begin{array}{c}\text { EPIDEMIOLOGIA EM SAÚDE } \\
\text { PÚBLICA }\end{array}$ & FUNDAÇÃO OSWALDO CRUZ & \multirow{4}{*}{ SAÚDE COLETIVA } & \multirow{8}{*}{ SAÚDE COLETIVA (VIII) } & 6 \\
\hline NUTRIÇÃO EMSAÚDE PÚBLICA & UNIVERSIDADE DE SÃO PAULO & & & 6 \\
\hline SAÚDE COLETIVA & $\begin{array}{l}\text { UNIVERSIDADE DO ESTADO DO } \\
\text { RIO DEJANEIRO }\end{array}$ & & & 7 \\
\hline SAÚDE COLETIVA & $\begin{array}{c}\text { UNIVERSIDADE FEDERAL DA } \\
\text { BAHIA }\end{array}$ & & & 7 \\
\hline SAÚDE PÚBLICA & FUNDACAO OSWALDO CRUZ & \multirow{4}{*}{ SAÚDE PÚBLICA } & & 6 \\
\hline SAÚDE PÚBLICA & UNIVERSIDADE DE SÃO PAULO & & & 6 \\
\hline SAÚDE PÚBLICA & $\begin{array}{l}\text { UNIVERSIDADE FEDERAL DE } \\
\text { MINAS GERAIS }\end{array}$ & & & 6 \\
\hline $\begin{array}{l}\text { SAÚDE PÚBLICA E MEIO } \\
\text { AMBIENTE }\end{array}$ & FUNDAÇÃO OSWALDO CRUZ & & & 6 \\
\hline
\end{tabular}

Fonte: Elaborada pelos autores. 
Observa-se que, geograficamente, a maior parte dos programas de pós-graduação do universo desta pesquisa $(68,75 \%)$ encontra-se na região Sudeste, seguidos pelas regiões Sul (18,75\%), Nordeste $(9,37 \%)$ e Centro-oeste $(3,12 \%)$, não havendo programas na região Norte neste recorte de pesquisa. Essa realidade se assemelha aos dados do último Censo do Ensino Superior do Instituto Nacional de Estudos e Pesquisas Educacionais Anísio Teixeira (INEP) com relação ao número de instituições de ensino superior (IES), no qual a região Sudeste abriga 48,04\% das IES brasileiras, a Nordeste, $18,09 \%$, a Sul, $17,51 \%$, a Centro-Oeste, $10,62 \%$ e a Norte, $5,74 \%$ (INEP, 2015).

Nesse cenário é possível observar a concentração tanto de IES como dos programas de exce- lência que compõem o recorte desta pesquisa na região Sudeste, que consiste na região mais populosa do país, responsável por $55,4 \%$ do Produto Interno Bruto (PIB) nacional (IBGE, 2010). Também é possível observar que, dentre as áreas básicas, a mais representativa é a da engenharia civil, concentrando seis programas, seguidos pelas áreas de saúde coletiva e saúde pública, cada qual com quatro programas.

A Tabela 4 apresenta a síntese dos dados relativos a cada programa, contendo: o número de publicações - teses e dissertações - encontrados na busca por palavra-chave; o endereço eletrônico do banco de dados acessado; o ano a partir do qual as publicações estão disponíveis; e o ano de criação destes programas.

Tabela 4 - Dados sobre os programas de excelência estudados.

\begin{tabular}{|c|c|c|c|c|c|c|}
\hline $\begin{array}{l}\text { Área } \\
\text { Avaliação } \\
\text { (*) }\end{array}$ & Nome do Programa & Instituição & $\begin{array}{l}N^{\circ} \text { de } \\
\text { Publicações }\end{array}$ & Endereço eletrônico do programa & $\begin{array}{c}\text { Origem da } \\
\text { disponibilidade das } \\
\text { teses e dissertações }\end{array}$ & $\begin{array}{l}\text { Ano de } \\
\text { Criação } \\
\text { do } \\
\text { Programa }\end{array}$ \\
\hline \multirow{3}{*}{ (I) } & Ciência Ambiental & USP-IEE & 10 & http://www.iee.usp.br/pos/?q=procam & 1994 & 1990 \\
\hline & $\begin{array}{l}\text { Desenvolvimento } \\
\text { Sustentável }\end{array}$ & UNB & 20 & $\begin{array}{l}\text { http://www.cds.unb.br/cds/portal2/ } \\
\text { index.php/pt/pos-graduacao }\end{array}$ & *Não Disponível & 1996 \\
\hline & Ecologia Aplicada & USP-ESALQ & 1 & $\begin{array}{l}\text { http://www4.esalq.usp.br/pg/ } \\
\text { programas/ecologia-aplicada }\end{array}$ & *Não Disponível & 2001 \\
\hline \multirow{3}{*}{ (II) } & Administração & FGV-RJ & 1 & $\begin{array}{c}\text { http://ebape.fgv.br/programas/ } \\
\text { mestrado\%20academico\%20 } \\
\text { doutorado/apresentacao }\end{array}$ & 2003 & 1967 \\
\hline & Administração & UFMG & 1 & http://www.cepead.face.ufmg.br/ & *Não Disponível & 1973 \\
\hline & Administração de Empresas & FGV-SP & 5 & http://cmcd.fgv.br/CMAE & 1940 & 1974 \\
\hline \multirow{3}{*}{ (III) } & $\begin{array}{l}\text { Política Científica e } \\
\text { Tecnológica }\end{array}$ & UNICAMP & 5 & $\begin{array}{l}\text { http://www.ige.unicamp.br/pos- } \\
\text { graduacao/politica-cientifica-e- } \\
\text { tecnologica/ }\end{array}$ & 2005 & 1988 \\
\hline & $\begin{array}{l}\text { Políticas Públicas e } \\
\text { Formação Humana }\end{array}$ & UERJ & 0 & http://ppfh.com.br/pt_BR/ & 2009 & 2005 \\
\hline & $\begin{array}{c}\text { Interdisciplinar em Ciências } \\
\text { Humanas }\end{array}$ & UFSC & 0 & $\begin{array}{c}\text { http://ppgich.ufsc.br/sobre-o-curso/ } \\
\text { apresentacao/ }\end{array}$ & 1999 & 1995 \\
\hline \multirow{2}{*}{ (IV) } & Demografia & UNICAMP & 0 & $\begin{array}{l}\text { http://www.ifch.unicamp.br/ifch/pos/ } \\
\text { demografia }\end{array}$ & 2005 & 1982 \\
\hline & Demografia & UFMG & 1 & $\begin{array}{l}\text { http://www.cedeplar.ufmg.br/ } \\
\text { demografia/apresentacao.html }\end{array}$ & 1968 & 1989 \\
\hline \multirow{6}{*}{$(\mathrm{V})$} & Engenharia Civil & PUC-RJ & 13 & $\begin{array}{l}\text { http://www.puc-rio.br/ensinopesq/ } \\
\text { ccpg/progciv.html }\end{array}$ & 1966 & 1965 \\
\hline & Engenharia Civil & UFSC & 12 & http://ppgec.posgrad.ufsc.br/?lang=pt & 2002 & 1991 \\
\hline & Engenharia Civil & UFRJ & 57 & http://www.coc.ufrj.br/ & 1968 & 1968 \\
\hline & Engenharia Civil & UFRGS & 18 & http://www.ufrgs.br/engcivil/ppgec/ & "Não Disponível & 1970 \\
\hline & $\begin{array}{c}\text { Engenharia Civil (Recursos } \\
\text { Hídricos) }\end{array}$ & UFC & 31 & http://hidro.deha.ufc.br/posdeha/ & 2000 & 1972 \\
\hline & $\begin{array}{c}\text { Recursos Hídricos e } \\
\text { Saneamento Ambiental }\end{array}$ & UFRGS & 24 & http://www.ufrgs.br/ppgiph & 1970 & 1969 \\
\hline
\end{tabular}

Continua... 
Continuação...

\begin{tabular}{|c|c|c|c|c|c|c|}
\hline $\begin{array}{c}\text { Área } \\
\text { Avaliação } \\
(*)\end{array}$ & Nome do Programa & Instituiç̧ão & $\begin{array}{l}N^{\circ} \text { de } \\
\text { Publicações }\end{array}$ & Endereço eletrônico do programa & $\begin{array}{c}\text { Origem da } \\
\text { disponibilidade das } \\
\text { teses e dissertações }\end{array}$ & $\begin{array}{c}\text { Ano de } \\
\text { Criação } \\
\text { do } \\
\text { Programa }\end{array}$ \\
\hline \multirow[b]{2}{*}{ (V) } & $\begin{array}{l}\text { Engenharia Hidráulica e } \\
\text { Saneamento }\end{array}$ & USP-EESC & 102 & http://www1.eesc.usp.br/ppgshs/ & 1970 & 1970 \\
\hline & $\begin{array}{c}\text { Saneamento, Meio } \\
\text { Ambiente e Recursos } \\
\text { Hídricos }\end{array}$ & UFMG & 102 & http://www.smarh.eng.ufmg.br/ & 1976 & 1972 \\
\hline \multirow{3}{*}{$(\mathrm{Vl})$} & Engenharia de Produção & UFPE & 1 & https://www.ufpe.br/ppgepcaa/ & 2015 & 2012 \\
\hline & Engenharia de Produção & UFRGS & 1 & http://www.ufrgs.br/producao/ & 1995 & 1991 \\
\hline & Planejamento Energético & UFRJ & 22 & http://www.ppe.ufrj.br/ & 1979 & 1979 \\
\hline \multirow{2}{*}{ (VII) } & $\begin{array}{l}\text { Planejamento Urbano e } \\
\text { Regional }\end{array}$ & UFRJ & 2 & http://www.ippur.ufrj.br/ & $\begin{array}{l}\text { "Base Minerva - Não } \\
\text { Disponível }\end{array}$ & 1971 \\
\hline & $\begin{array}{c}\text { Planejamento Urbano e } \\
\text { Regional }\end{array}$ & UFRGS & 3 & http://www.ufrgs.br/propur/ & 1973 & 1970 \\
\hline \multirow{8}{*}{ (VIII) } & $\begin{array}{l}\text { Epidemiologia em Saúde } \\
\text { Pública }\end{array}$ & FIOCRUZ & 0 & $\begin{array}{l}\text { http://www.ensp.fiocruz.br/portal- } \\
\text { ensp/pos-graduacao/site/?site=3 }\end{array}$ & 2007 & 2007 \\
\hline & Nutrição em Saúde Pública & USP-FSP & 0 & http://www.fsp.usp.br/pos/?cat=27 & 2007 & 2007 \\
\hline & Saúde Coletiva & UERJ & 0 & http://www.ims.uerj.br/ & 1994 & 1987 \\
\hline & Saúde Coletiva & UFBA & 2 & http://www.isc.ufba.br/ & 1977 & 1973 \\
\hline & Saúde Pública & FIOCRUZ & 47 & $\begin{array}{l}\text { http://www.ensp.fiocruz.br/portal- } \\
\text { ensp/pos-graduacao/site/?site=1; } \\
\text { https://www.arca.fiocruz.br/ }\end{array}$ & 1977 & 1977 \\
\hline & Saúde Pública & USP-FSP & 25 & http://www.fsp.usp.br/pos/?cat=26 & 1970 & 1970 \\
\hline & Saúde Pública & UFMG & 0 & $\begin{array}{l}\text { http://site.medicina.ufmg.br/ } \\
\text { cpgsaudepublica/ }\end{array}$ & 1995 & 1994 \\
\hline & $\begin{array}{l}\text { Saúde Pública e Meio } \\
\text { Ambiente }\end{array}$ & FIOCRUZ & 39 & $\begin{array}{l}\text { http://www.ensp.fiocruz.br/portal- } \\
\text { ensp/pos-graduacao/site/?site=2 }\end{array}$ & 2006 & 2006 \\
\hline
\end{tabular}

(*) Conforme classificação da Tabela 3

Fonte: Elaborada pelos autores.

$\mathrm{Na}$ apresentação das publicações por programa é importante destacar os dois programas de engenharia sanitária que compõem o recorte estudado - da Universidade de São Paulo, campus São Carlos, e da Universidade Federal de Minas Gerais - como aqueles com maior número de publicações individualmente - 102 cada -, sendo representativos no contexto da pós-graduação de excelência internacional em resíduos sólidos. Vale destacar também que esses programas figuram entre os mais antigos do universo de análise e apresentam linha de pesquisa específica na área de resíduos sólidos, como componente básico da engenharia sanitária.

Ainda com relação à análise específica dos programas, observa-se que oito daqueles definidos no universo da pesquisa não apresentaram nenhuma ocorrência de publicação com os termos de busca definidos, representando $25 \%$ do uni- verso. Esses programas pertencem a três áreas de avaliação: interdisciplinar (2); demografia (1); e saúde coletiva (5), o que pode ser devido à interdisciplinaridade dessas áreas em particular, assim como nas linhas de pesquisa dos programas.

A Tabela 4 também apresenta os dados relativos à origem de dispoinibilidade das teses e dissertações e o ano de criação de cada programa. Esse levantamento permitiu avaliar que, em alguns casos, a busca nas plataformas digitais apresenta limitações, visto que alguns programas possuem um banco de dados de teses e dissertações que não disponibilizam trabalhos mais antigos, como Engenharia Civil (UFSC); Engenharia Civil Recursos Hídricos (UFC); Demografia (UNICAMP); Saúde Coletiva (UERJ); Administração (FGV-RJ); Administração de Empresas (FGV-SP); e Política Científica e Tecnológica (UNICAMP). 
Os dados dos programas de pós-graduação também foram analisados em função das áreas básicas - que permitem maior refinamento se comparadas às áreas de avaliação - e os resultados são apresentados na Tabela 5. Nesta seleção foi avaliado, em cada um dos programas de excelência internacional, o número de dissertações e teses publicadas encontradas por meio de um ou mais termos de busca. De forma complementar foram identificados os pesquisadores que orientaram na área de resíduos sólidos.

Tabela 5 - Dados gerais referentes aos programas identificados, separados por área básica.

\begin{tabular}{|c|c|c|c|c|}
\hline Área Básica & Programas Ativos & Programas de Excelência & $\begin{array}{l}\text { Publicações na Área de } \\
\text { Resíduos Sólidos }\end{array}$ & $\begin{array}{l}\text { Pesquisadores que } \\
\text { orientaram na Área de } \\
\text { Resíduos Sólidos }\end{array}$ \\
\hline ENGENHARIA CIVIL & 62 & 6 & 155 & 50 \\
\hline ENGENHARIA SANITÁRIA & 32 & 2 & 204 & 43 \\
\hline ENGENHARIA DE PRODUÇÃO & 47 & 3 & 24 & 10 \\
\hline SAÚDE COLETIVA & 70 & 4 & 2 & 1 \\
\hline SAÚDE PÚBLICA & 26 & 4 & 64 & 32 \\
\hline DEMOGRAFIA & 4 & 2 & 1 & 1 \\
\hline PLANEJAMENTO URBANO E REGIONAL & 43 & 2 & 5 & 4 \\
\hline CIÊNCIAS AMBIENTAIS & 117 & 3 & 31 & 16 \\
\hline ADMINISTRAÇÃO & 126 & 3 & 7 & 7 \\
\hline SOCIAIS E HUMANIDADES & 133 & 3 & 5 & 4 \\
\hline Totais & 660 & 32 & 498 & 168 \\
\hline
\end{tabular}

Fonte: Elaborada pelos autores.

Os programas avaliados compõem um total de 498 dissertações e teses na área de resíduos sólidos, contando com 168 pesquisadores que orientaram na área. Com relação às Áreas Básicas com maior número de produções têm-se, por ordem decrescente: Engenharia Sanitária (40,96\%); Engenharia Civil (31,12\%); Saúde Pública (12,85\%); Ciências Ambientais (6,22\%); e Engenharia de Produção (4,82\%), tendo as demais áreas menos de 10 publicações cada.

Observa-se que $76,9 \%$ da produção é advinda de programas das áreas de engenharia analisados nesta pesquisa (sanitária, civil e produção). Esse fato contrapõe a percepção apresentada por Velloso (2008), na qual a área da saúde pública abrigou ao longo do tempo as atividades e o interesse pela temática dos resíduos sólidos, havendo nas últimas décadas um deslocamento do eixo das pesquisas para áreas mais técnicas ou operacionais. A inserção da pesquisa científica e da formação de recursos humanos quali- ficados para a abordagem técnica dos resíduos sólidos consubstancia o caráter interdisciplinar da área.

Comparativamente, os menores percentuais de produção em programas de excelência nas áreas de ciências ambientais, administração e humanidades podem revelar uma discrepância no percentual de programas de excelência por área de avaliação e a consequente concentração desigual de programas e pesquisas nas áreas. Em decorrência desse fato, a abordagem da temática pode se mostrar insuficiente, pois vai muito além dos aspectos técnicos relativos à engenharia, como já destacado por Tchobanoglous, Theisen e Vigil em 1993.

A Fig. 3 apresenta a espacialização das publicações (teses e dissertações) dos programas de pós-graduação de excelência na área de resíduos sólidos. 


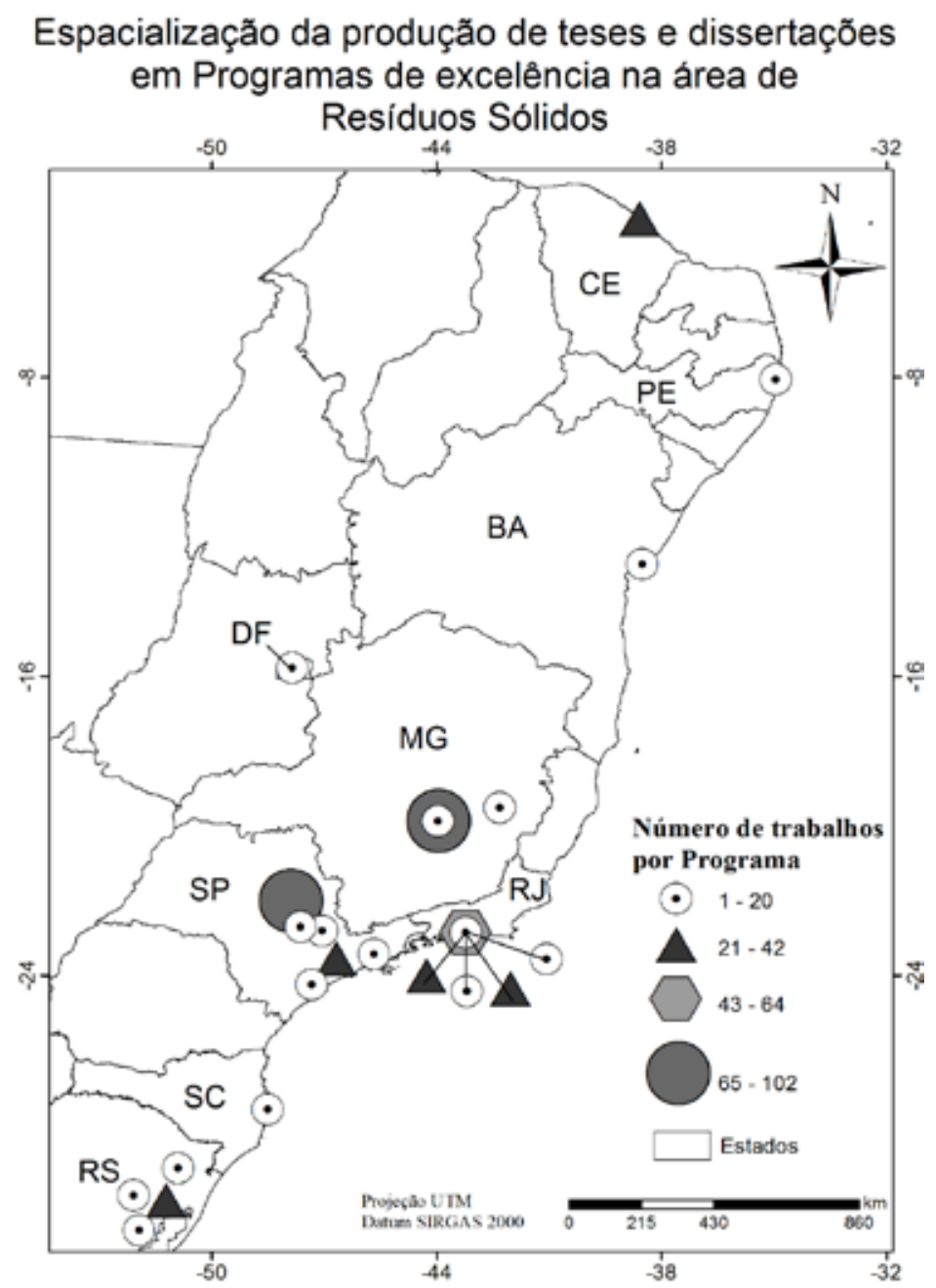

Figura 3 - Espacialização das teses e dissertações dos programas de pós-graduação de excelência na área de resíduos sólidos. Fonte: Elaborada pelos autores.

A análise dos resultados espacializados evidencia a predominância da ocorrência de produção na área nos estados de São Paulo, Minas Gerais e Rio de Janeiro. Não obstante, é necessário destacar a representatividade dos programas de pós-graduação de instituições do Ceará e do Rio Grande do Sul, sendo que os demais estados contribuem com menor número de publicações neste universo. É válido reiterar o fato de que o recorte desta pesquisa consiste em programas de excelência internacional, o que não significa que não haja produção na área de resíduos sólidos nos demais programas de pós-graduação ou nos estados não representados nesta espa- cialização. Os dados e as informações analisados nesta pesquisa referem-se unicamente ao estrato selecionado.

Ressalta-se que ao longo da análise dos dados foi identificada uma quantidade expressiva de pesquisadores com orientações pontuais de teses e dissertações na área. Tal fato pode ser observado nos dados apresentados na Tabela 5, que aponta uma média de 2,96 orientações por pesquisador. Por outro lado, foi possível identificar seis pesquisadores $(3,6 \%)$ com histórico significativo de orientações nestes programas, sendo que a Fig. 4 apresenta os pesquisadores com mais de dez orientações na área. 


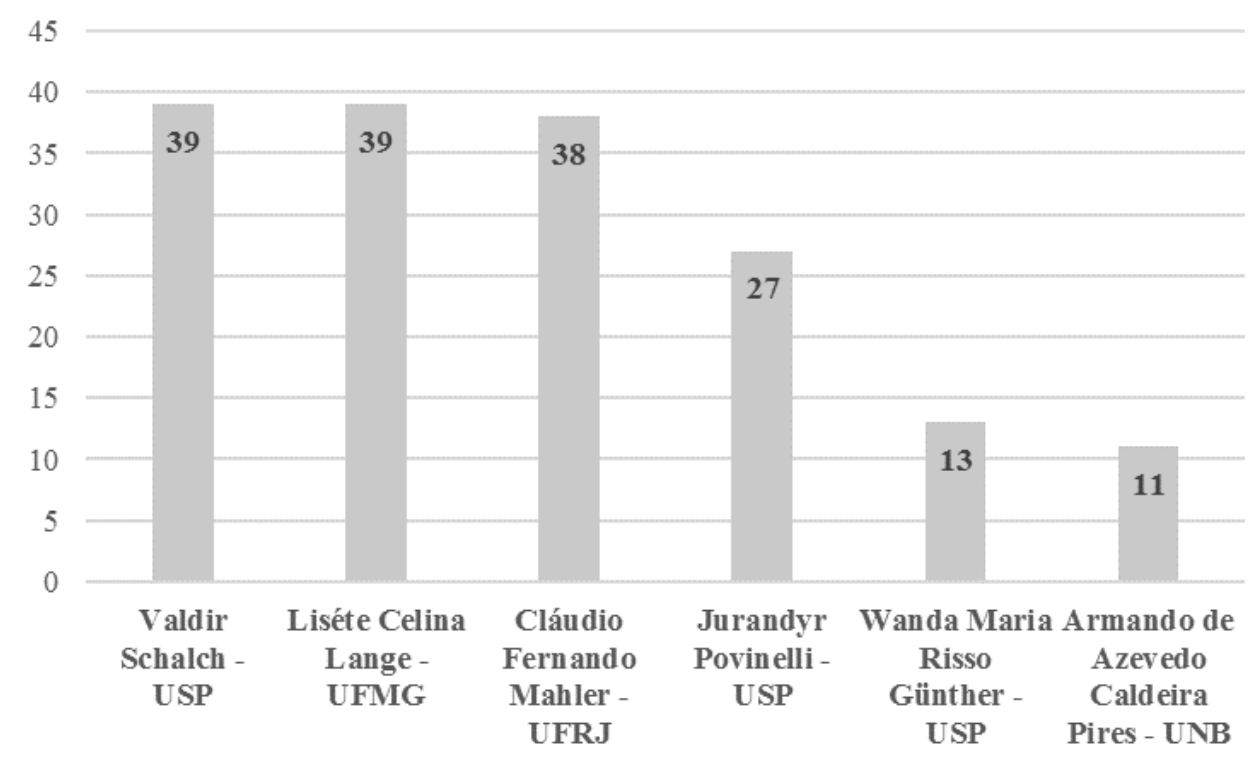

Figura 4 - Pesquisadores com mais de dez orientações em dissertações e teses na área de resíduos sólidos em programas de excelência internacional.

Fonte: Elaborada pelos autores.

Ao longo da carreira acadêmica, esses pesquisadores concluíram a orientação de 167 dissertações e teses nos programas analisados, ou seja, $33,6 \%$ do total. Neste sentido, excetuando-se esses pesquisadores da amostra, a média de orientação diminui para 2,03 orientações por pesquisador.

As médias de 2,96 e 2,03 (excetuando-se os seis pesquisadores apresentados na Figura 4) de orientações por pesquisador podem indicar a inserção de novos pesquisadores nos programas analisados, orientações pontuais ou ainda orientações com abordagens específicas na área de resíduos sólidos, impactando na interdisciplinaridade da área.
Outro eixo de análise desta pesquisa originou-se a partir das buscas realizadas nos endereços eletrônicos de cada programa de Pós-Graduação, pois foi possível a identificação de elementos dos bancos de dados dos programas, que são apresentados na Tabela 6.

Os dados são apresentados destacando-se a forma e o mecanismo de busca das teses e dissertações dos programas, além da disponibilidade dos dados - que levou em consideração a possibilidade de download dos trabalhos dentro dos sites dos programas de Pós-Graduação - bem como a identificação clara das linhas de pesquisa dos programas. 
Tabela 6 - Elementos dos bancos de dados dos programas de Pós-Graduação identificados.

\begin{tabular}{|c|c|c|c|c|c|}
\hline Programa & Instituiç̧ão & Forma de Busca & Mecanismo de busca & $\begin{array}{l}\text { Disponibilidade } \\
\text { dos Dados }\end{array}$ & $\begin{array}{l}\text { Identificação } \\
\text { de linhas de } \\
\text { pesquisa }\end{array}$ \\
\hline Ciência Ambiental & USP-IEE & $\begin{array}{l}\text { Biblioteca Digital de Teses } \\
\text { e Dissertações da USP }\end{array}$ & $\begin{array}{l}\text { Busca avançada (Nome; Orientador; } \\
\text { Título; Ano; Programa) }\end{array}$ & Sim & Sim \\
\hline $\begin{array}{l}\text { Desenvolvimento } \\
\text { Sustentável }\end{array}$ & UNB & Direto em página do site & $\begin{array}{c}\text { Busca avançada (Nome; Orientador; } \\
\text { Título) }\end{array}$ & Parcial* & Sim \\
\hline Ecologia Aplicada & USP-ESALQ & $\begin{array}{l}\text { Biblioteca Digital de Teses } \\
\text { e Dissertações da USP }\end{array}$ & $\begin{array}{c}\text { Busca avançada (Nome; Orientador; } \\
\text { Título; Ano; Programa) }\end{array}$ & Sim & Sim \\
\hline Administração & FGV-RJ & $\begin{array}{l}\text { Direciona para outro site } \\
\text { (Sistema de Bibliotecas } \\
\text { FGV) }\end{array}$ & $\begin{array}{l}\text { Busca avançada (Nome; Orientador; } \\
\text { Título; Ano; Assunto) }\end{array}$ & Sim & Sim \\
\hline Administração & UFMG & Direto em página do site & Busca simples (Termo a ser pesquisado) & Sim & Sim \\
\hline Administração de Empresas & FGV-SP & $\begin{array}{l}\text { Direciona para outro site } \\
\text { (Sistema de Bibliotecas } \\
\text { FGV) }\end{array}$ & $\begin{array}{l}\text { Busca avançada (Nome; Orientador; } \\
\text { Título; Ano; Assunto; Idioma) }\end{array}$ & Não & Sim \\
\hline $\begin{array}{l}\text { Política Científica e } \\
\text { Tecnológica }\end{array}$ & UNICAMP & $\begin{array}{l}\text { Direciona para outro site } \\
\text { (Biblioteca Digital da } \\
\text { UNICAMP) }\end{array}$ & $\begin{array}{l}\text { Busca avançada (Nome; Orientador; } \\
\text { Título; Ano; Assunto; Resumo; Palavra- } \\
\text { chave; Instituto/Faculdade; Área de } \\
\text { Concentração) }\end{array}$ & Não & Sim \\
\hline $\begin{array}{l}\text { Políticas Públicas e } \\
\text { Formação Humana }\end{array}$ & UERJ & Direto em página do site & $\begin{array}{l}\text { Busca simples (Título ou Autor ou } \\
\text { Orientador) }\end{array}$ & Parcial*ar & Sim \\
\hline $\begin{array}{l}\text { Interdisciplinar em Ciências } \\
\text { Humanas }\end{array}$ & UFSC & Direto em página do site & $\begin{array}{l}\text { Busca dividida por ano - por meio de } \\
\text { cada título em cada ano }\end{array}$ & Sim & Sim \\
\hline Demografia & UNICAMP & Direto em página do site & $\begin{array}{l}\text { Busca por palavras-chave ou parte do } \\
\text { título }\end{array}$ & Sim & Parcial \\
\hline Demografia & UFMG & Direto em página do site & $\begin{array}{l}\text { Busca dividida por ano - por meio de } \\
\text { cada título em cada ano }\end{array}$ & Parcial* & Parcial*wo: \\
\hline Engenharia Civil & PUC-RJ & Direto em página do site & $\begin{array}{c}\text { Busca avançada (Nome; Título; Ano; } \\
\text { Linha de Pesquisa) }\end{array}$ & Parcial* & $\operatorname{Sim}$ \\
\hline Engenharia Civil & UFSC & Direto em página do site & $\begin{array}{l}\text { Busca por meio de cada título - não há } \\
\text { a possibilidade de busca por palavras- } \\
\text { chave ou parte do título }\end{array}$ & Sim & Parcial*;*; \\
\hline Engenharia Civil & UFRJ & Direto em página do site & $\begin{array}{l}\text { Busca dividida por ano - por meio de } \\
\text { cada título em cada ano }\end{array}$ & $\operatorname{Sim}$ & Sim \\
\hline Engenharia Civil & UFRGS & Direto em página do site & $\begin{array}{l}\text { Busca por meio de cada título - não há } \\
\text { a possibilidade de busca por palavras- } \\
\text { chave ou parte do título }\end{array}$ & Parcial* & Sim \\
\hline $\begin{array}{c}\text { Engenharia Civil (Recursos } \\
\text { Hídricos) }\end{array}$ & UFC & Direto em página do site & $\begin{array}{l}\text { Busca dividida por ano - por meio de } \\
\text { cada título em cada ano }\end{array}$ & Sim & Sim \\
\hline $\begin{array}{l}\text { Recursos Hídricos e } \\
\text { Saneamento Ambiental }\end{array}$ & UFRGS & Direto em página do site & $\begin{array}{l}\text { Busca dividida por ano - por meio de } \\
\text { cada título em cada ano }\end{array}$ & Sim & Sim \\
\hline $\begin{array}{l}\text { Engenharia Hidráulica e } \\
\text { Saneamento }\end{array}$ & USP-EESC & Direto em página do site & $\begin{array}{l}\text { Busca avançada (Nome; Orientador; } \\
\text { Título; Ano) }\end{array}$ & Não & 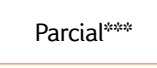 \\
\hline $\begin{array}{l}\text { Saneamento, Meio } \\
\text { Ambiente e Recursos } \\
\text { Hídricos }\end{array}$ & UFMG & Direto em página do site & $\begin{array}{l}\text { Busca avançada (Nome; Orientador; } \\
\text { Título; Ano) }\end{array}$ & Parcial* & Sim \\
\hline Engenharia de Produção & UFPE & Direto em página do site & $\begin{array}{l}\text { Lista com Título/Autor/Orientador por } \\
\text { ano }\end{array}$ & Não & Sim \\
\hline Engenharia de Produção & UFRGS & Direto em página do site & $\begin{array}{l}\text { Busca avançada (Nome; Orientador; } \\
\text { Título; Ano; Programa) }\end{array}$ & Sim & Não \\
\hline Planejamento Energético & UFRJ & Direto em página do site & $\begin{array}{l}\begin{array}{l}\text { Lista com Título/Autor/Orientador por } \\
\text { ano }\end{array}\end{array}$ & $\operatorname{Sim}$ & $\operatorname{Sim}$ \\
\hline $\begin{array}{l}\text { Planejamento Urbano e } \\
\text { Regional }\end{array}$ & UFRJ & $\begin{array}{l}\text { Direciona para outro site } \\
\text { (Biblioteca IPPUR - Base } \\
\text { Minerva) }\end{array}$ & Busca na biblioteca URFJ - IPPUR & Não & Sim \\
\hline $\begin{array}{l}\text { Planejamento Urbano e } \\
\text { Regional }\end{array}$ & UFRGS & Direto em página do site & $\begin{array}{l}\text { Busca dividida por ano - por meio de } \\
\text { cada título em cada ano }\end{array}$ & Parcial* & Sim \\
\hline $\begin{array}{l}\text { Epidemiologia em Saúde } \\
\text { Pública }\end{array}$ & FIOCRUZ & Acervo de Teses FIOCRUZ & $\begin{array}{l}\text { Busca por palavras-chave ou parte do } \\
\text { título }\end{array}$ & Sim & Sim \\
\hline Nutrição em Saúde Pública & USP-FSP & $\begin{array}{l}\text { Biblioteca Digital de Teses } \\
\text { e Dissertações da USP }\end{array}$ & $\begin{array}{l}\text { Busca avançada (Nome; Orientador; } \\
\text { Título; Ano; Programa) }\end{array}$ & Sim & Sim \\
\hline
\end{tabular}

Continua... 
Continuação...

\begin{tabular}{|c|c|c|c|c|c|}
\hline Programa & Instituiç̧ão & Forma de Busca & Mecanismo de busca & $\begin{array}{l}\text { Disponibilidade } \\
\text { dos Dados }\end{array}$ & $\begin{array}{l}\text { Identificação } \\
\text { de linhas de } \\
\text { pesquisa }\end{array}$ \\
\hline Saúde Coletiva & UERJ & Direto em página do site & $\begin{array}{l}\text { Busca dividida por Dissertações/Teses } \\
\text { e por ano - por meio de cada título em } \\
\text { cada ano }\end{array}$ & $\operatorname{Sim}$ & Parcial $* * ; *$ \\
\hline Saúde Coletiva & UFBA & $\begin{array}{l}\text { Direciona para outro site } \\
\text { (Repositório Institucional } \\
\text { - UFBA) }\end{array}$ & $\begin{array}{l}\text { Busca avançada (Nome; Orientador; } \\
\text { Título; Ano; Programa) }\end{array}$ & $\operatorname{Sim}$ & Sim \\
\hline Saúde Pública & FIOCRUZ & Acervo de Teses FIOCRUZ & $\begin{array}{l}\text { Busca por palavras-chave ou parte do } \\
\text { título }\end{array}$ & Sim & Sim \\
\hline Saúde Pública & USP-FSP & $\begin{array}{l}\text { Biblioteca Digital de Teses } \\
\text { e Dissertações da USP }\end{array}$ & $\begin{array}{l}\text { Busca avançada (Nome; Orientador; } \\
\text { Título; Ano; Programa) }\end{array}$ & Sim & Sim \\
\hline Saúde Pública & UFMG & $\begin{array}{c}\text { Site apresenta lista com } \\
\text { teses e dissertações - } \\
\text { busca feita na Biblioteca } \\
\text { Digital - UFMG }\end{array}$ & $\begin{array}{l}\text { Busca avançada (Nome; Orientador; } \\
\text { Título; Ano; Programa) }\end{array}$ & Sim & Parcial $^{* * ; * * ;}$ \\
\hline $\begin{array}{l}\text { Saúde Pública E Meio } \\
\text { Ambiente }\end{array}$ & FIOCRUZ & Acervo de Teses FIOCRUZ & $\begin{array}{l}\text { Busca por palavras-chave ou parte do } \\
\text { título }\end{array}$ & Sim & Sim \\
\hline $\begin{array}{l}\text { Epidemiologia em Saúde } \\
\text { Pública }\end{array}$ & FIOCRUZ & Acervo de Teses FIOCRUZ & $\begin{array}{c}\text { Busca por palavras-chave ou parte do } \\
\text { título }\end{array}$ & Sim & Sim \\
\hline Nutrição em Saúde Pública & USP-FSP & $\begin{array}{l}\text { Biblioteca Digital de Teses } \\
\text { e Dissertações da USP }\end{array}$ & $\begin{array}{l}\text { Busca avançada (Nome; Orientador; } \\
\text { Título; Ano; Programa) }\end{array}$ & Sim & Sim \\
\hline
\end{tabular}

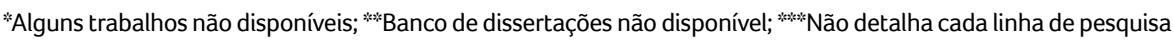

Fonte: Elaborada pelos autores.

Analisando-se os dados sistematizados, é possível observar que cada programa e sua respectiva plataforma de dissertações e teses possui particularidades, em especial quanto às buscas e disponibilidade de informações e materiais. As linhas de pesquisa de cada programa foram apresentadas com detalhamento em 25 dos 32 programas analisados. Porém a disponibilidade de download das teses e dissertações foi possível em $65,6 \%$ dos sites dos programas de pós-graduação. Nesse sentido, pode-se apontar uma limitação das buscas por meio de plataformas digitais, onde algumas apresentam mecanismos simples que permitem a busca apenas pelo título ou autor do trabalho; e outras, avançados, com um acervo maior de informações, como Nome; Orientador; Título; Ano; Assunto; Resumo; Palavra-chave; Instituto/Faculdade; Área de Concentração. Ainda nesse sentido destaca-se que em alguns programas, dissertações e teses mais antigas não estão digitalizadas e disponíveis nas plataformas dos programas.

\section{CONCLUSÕES}

A questão acerca da interdisciplinaridade da área de resíduos sólidos, permeada em diversas áreas do conhecimento, ficou evidente ao se constatar que todas as áreas básicas de avaliação da CAPES selecionadas no presente artigo apresentam pesquisas relacionadas à temática em questão.

Ainda, por conta da interdisciplinaridade, notase um número expressivo de pesquisadores que orientam teses e dissertações na área de resíduos sólidos em programas de excelência internacional. Porém, sob um olhar mais apurado, é possível constatar a concentração de orientação - 33,6\% - nas publicações analisadas em seis pesquisadores e orientações pontuais realizadas por outros pesquisadores.

Com relação à disponibilidade das teses e dissertações produzidas nos programas de excelência analisados, foi possível observar que há grande heterogeneidade nos formatos das plataformas eletrônicas de busca, até mesmo em 
programas oriundos da mesma instituição, o que pode dificultar ou mesmo inviabilizar pesquisas similares a esta. Ainda com relação à disponibilidade dos dados, teses e dissertações mais antigas são encontradas somente em meio físico, não estando digitalizadas ou disponíveis para download nas plataformas.

A espacialização da produção de teses e dissertações na área de resíduos sólidos em programas de excelência internacional indica uma assimetria significativa com concentração de trabalhos na região Sudeste - particularmente nos programas de engenharia sanitária, principais representantes das produções alvo desta pesquisa -, assim como a existência de pesquisas nas regiões Sul e Nordeste, em diferentes áreas do conhecimento. Ressalta-se o recorte desta pesquisa em programas de excelência internacional, de modo que não se afirma que não há produção na área de resíduos sólidos nos programas e estados não representados na espacialização.

Desta forma, conclui-se que a abordagem da temática dos resíduos sólidos está distribuída em diversas áreas do conhecimento, recebendo abordagens diversas e analisada a partir de diferentes perspectivas ou óticas. No entanto, no âmbito dos programas de pós-graduação de excelência internacional inseridos nesta pesquisa, é possível perceber em maior grau a produção na área nas áreas de engenharia, em oposição à abordagem existente até a década de 1950, na qual a temática era mais frequente em estudos da área de saúde pública. Esse fato corrobora o início da pesquisa científica no país, e da consolidação do ensino superior e dos programas de pós-graduação, promovendo a ampliação do número de pesquisadores e grupos de pesquisa, assim como da abordagem promovida à temática de resíduos sólidos.

Por fim, ressalta-se que áreas interdisciplinares como a de resíduos sólidos necessitam de ações que incentivem essa abordagem interdisciplinar, possibilitando pesquisas interinstituições, envolvendo diferentes áreas, bem como o trabalho em rede de diferentes pesquisadores, a fim de suplementar o conhecimento compartimentalizado e efetivamente contribuir para questões práticas relativas aos resíduos sólidos.

\section{REFERÊNCIAS}

ACCURIO, G.; ROSSIN, A.; TEIXEIRA, P. F.; ZEPEDA, F., Diagnóstico de La Situación del Manejo de Residuos Sólidos Municipales en América Latina y El Caribe. Organización Panamericana de la Salud/Organización Mundial de La Salud, Serie Ambiental no 18. Washington, DC: OPAS/OMS. 1998.

BIOLCHINI, J.; MIAN, P. G.; NATALI, A. C. C., CONTE, T. U.; TRAVESSOS, G. H. Scientific research ontology to support systematic review in software engineering. Advanced Engineering Informatics, v. 21, n. 2, 133-151, 2007.

BRASIL. Ministério da Educação. Portaria n 1.418/1998. Estabelece a classificação dos cursos de Pós-Graduação stricto sensu. DOU 24/12/1998.

Decreto no 21.321, de 18 de junho de 1946. Aprova o Estatuto da Universidade do Brasil. Diário Oficial da União - Seção 1 - 20/6/1946, Página 9256 (Publicação Original).

BUSS, P. M. Desenvolvimento, Ambiente e Saúde. Ciência \& Ambiente, v. 25, p. 9-32. 2002.

CONFERÊNCIA DAS NAÇÕES UNIDAS SOBRE MEIO AMBIENTE E DESENVOLVIMENTO (CNUMAD). Agenda 21. Rio de Janeiro, Brasil, 3-14 jun 1992.

CACETE, N. H. Breve história do ensino superior brasileiro e da formação de professores para a escola secundária. Educ. Pesqui., São Paulo, v. 40, n. 4, p. 1061-1076, out./dez. 2014.

COORDENAÇÃO DE APERFEIÇOAMENTO DE PESSOAL DE NÍVEL SUPERIOR (CAPES). Sobre as áreas de avaliação. 2016a. Disponível em: <https://goo.gl/tOofxi>. Acesso em 25 jun 2016.

Tabela de Áreas de Conhecimento/Avaliação. 2016b. Disponível em: <https://goo.gl/x5tlbP>. Acesso em 25 jun 2016.

Comissão Especial de Acompanhamento do PNPG 2011-2020 e Elaboração da Agenda Nacional de Pesquisa. Relatório Final - 2013. Brasília, novembro/2013. 104p. Disponível em: <goo.gl/qOr9aN>. Acesso em 29 ago 2016.

CORNIERI, M. G.; FRACALANZA, A. P. Desafios do lixo em nossa sociedade. Revista Brasileira de Ciências Ambientais, São Paulo, n. 16, p. 57-64, 2010. 
DODMAN, D.; MCGRANAHAN, G.; DALAL-CLAYTON, B. Integrating the environment in urban planning and management: key principles and approaches for cities in the $21^{\text {st }}$ century. Nairobi: United Nations Environment Programme (UNEP), 2013. Disponível em: http://goo.gl/dc8krU. Acesso em 30 mai. 2016.

FERREIRA, J.A., ANJOS, L.A. Aspectos de saúde coletiva e ocupacional associados à gestão dos resíduos sólidos municipais. Cad. Saúde Pública, Rio de Janeiro, 17(3): 689-696, mai-jun, 2001.

FONSECA, A. P. Prefácio. In: PHILIPPI JR., A.; TUCCI, C. E. M.; HOGAN, D. J.; NAVEGANTES, R. (Eds.). Interdisciplinaridade em Ciência Ambientais. São Paulo: Signus Editora, 2000.

INSTITUTO BRASILEIRO DE GEOGRAFIA E ESTATÍSTICA (IBGE). Censo Demográfico 2010. Disponível em http://goo.gl/xy58iO. Acesso em out 2016.

INSTITUTO NACIONAL DE ESTUDOS E PESQQUISAS EDUCACIONAIS ANÍSIO TEIXEIRA (INEP). Censo da educação superior 2013: Resumo Técnico. Brasília, 80p. 2015.

JACOBI, P. R. Desafios e reflexões sobre resíduos sólidos nas cidades brasileiras. In: SANTOS, M. C. L.; GONÇALVES-DIAS, S. L. F. Resíduos sólidos urbanos e seus impactos socioambientais. Instituto de Energia e Ambiente - Universidade de São Paulo (IEE-USP), São Paulo, 2012. p. 31-34.

LEFF, E. Complexidade, Interdisciplinaridade e Saber Ambiental. In: PHILIPPI JR., A.; TUCCI, C. E. M.; HOGAN, D. J.; NAVEGANTES, R. (Eds.). Interdisciplinaridade em Ciência Ambientais. São Paulo: Signus Editora, 2000.

MARQQUES, L. Lixo, efluentes e intoxicação industrial. In:

Capitalismo e colapso ambiental. Campinas: Editora da UNICAMP, 2015. p. 161-212.

MARSHALL, R. E.; FARAHBAKHSH, K. Systems approaches to integrated solid waste management in developing countries. Waste Management, v. 33, n. 4, p. 988-1003, 2013.

MARTINS, C.B. A Reforma Universitária de 1968 e a abertura para o ensino superior privado no Brasil. Educ. Soc., Campinas, vol. 30, n. 106, p. 15-35, jan./abr. 2009.

MAVROPOULOS, A.; TSAKONA, M.; ANTHOULI, A. Urban waste management and the mobile challenge. Waste Management \& Research, v. 33, n. 4, p. 381-387, 2015.
MESJASZ-LECH, A. Municipal waste management in context of sustainable urban development. Procedia-Social and Behavioral Sciences, v. 151, p. 244-256, 2014.

PHILIPPI JR., A. Interdisciplinaridade como atributo da C\&T. In: PHILIPPI JR., A.; TUCCI, C. E. M.; HOGAN, D. J.; NAVEGANTES, R. (Eds.). Interdisciplinaridade em Ciências Ambientais. São Paulo: Signus Editora, 2000. p. 3-16.

SANTOS, A.F.L.; AZEVEDO, J.M.L. A pós-graduação no Brasil, a pesquisa em educação e os estudos sobre a política educacional: os contornos da constituição de um campo acadêmico. Revista Brasileira de Educação v. 14 n. 42 set./dez. 2009.

SANTOS, C.M. Tradições e contradições da Pós-graduação no Brasil. Educação \& Sociedade, Campinas, vol. 24, n. 83, p. 627641, agosto 2003.

SANTOS, M. C. L.; GONÇALVES-DIAS, S. L. F. (Org.). Resíduos sólidos urbanos e seus impactos socioambientais. São Paulo: IEE-USP, 2012. 82p.

SENG, B., KANEKO, H., HIRAYAMA, K.; KATAYAMA-HIRAYAMA, K. Municipal solid waste management in Phnom Penh, capital city of Cambodia. Waste management \& research, v. 29, n. 5. p.491500. 2010.

SILVA, C. L.; FUGII, G. M.; SANTOYO, A. H.; BASSI, N. S.; VASCONCELOS, M. C.. Gestão de Resíduos Sólidos Urbanos em Capitais Brasileiras Alternativas para um Modelo de Gestão. Revista Brasileira de Ciências Ambientais, n. 33, p.118-132, 2014.

SISINNO, C. L. S.; OLIVEIRA, R. M. Impacto Ambiental dos Grandes Depósitos de Resíduos Urbanos e Industriais. In: . (Orgs.). Resíduos sólidos, ambiente e saúde: uma visão multidisciplinar. Rio de Janeiro: Editora Fiocruz, 2000. p. 59-78.

TCHOBANOGLOUS, G; THEISEN, H; VIGIL, S. Integrated Solid Waste Management: Engineering Principles and Management Issues. New York, NY: Irwin McGraw-Hill, 1993.

VELLOSO, A. A pós-graduação no Brasil: legados e desafios. Almanaque Multidisciplinar de Pesquisa. V.1, n.1, p. 4-15, 2014.

VELLOSO, M. P. Os restos na história: percepções sobre resíduos. Ciência \& Saúde Coletiva, v. 13, n. 6, p. 1953-1964, 2008.

ZVEIBIL, V.Z. Gestão dos Resíduos Sólidos - Novos paradigmas associados à saúde e ao meio ambiente. Ciência \& Ambiente, v. 25, p. 59-70. 2002. 